\title{
Mechanisms of metformin inhibiting lipolytic response to isoproterenol in primary rat adipocytes
}

\author{
Tingting Zhang ${ }^{1,2}$, Jinhan $\mathrm{He}^{1}$, Chong $\mathrm{Xu}^{1}$, Luxia $\mathrm{Zu}^{1}$, Hongfeng Jiang ${ }^{1}$, Shenshen $\mathrm{Pu}^{1}$, \\ Xiaohui Guo ${ }^{2}$ and Guoheng $\mathbf{X u}^{1}$ \\ ${ }^{1}$ Department of Physiology and Pathophysiology, Peking University Health Science Center, 38 Xueyuan Road, Beijing 100191, China \\ ${ }^{2}$ Department of Endocrinology, The First Hospital of Peking University, 8 Xishiku Street, Beijing 100034, China \\ (Correspondence should be addressed to G Xu; Email: xug@ bjmu.edu.cn)
}

$\mathrm{J} \mathrm{He}$ is now at Department of Pharmaceutical Sciences, Center for Pharmacogenetics, University of Pittsburgh, 659 Salk Hall, Pittsburgh, Pennsylvania 15213, USA

\begin{abstract}
The mobilization of free fatty acids (FFA) from adipose tissue to the bloodstream primarily depends on triacylglycerol lipolysis in adipocytes. Catecholamines are major hormones that govern lipolysis through elevating cellular cAMP production and activating protein kinase, cAMP dependent, catalytic, alpha (PKA) and mitogen-activated protein kinase 1/2 (MAPK1/3). Obesity and type 2 diabetes are associated with elevated levels of systemic FFA, which restricts glucose utilization and induces insulin resistance. The biguanide metformin exerts its antihyperglycemic effect by enhancing insulin sensitivity, which is associated with decreased levels of circulating FFA. In this study, we examined the characteristics and basis of the inhibitory effect of metformin on adrenergic-stimulated lipolysis in primary rat adipocytes. We measured the release of FFA and glycerol as an index of lipolysis and examined the major signalings of the lipolytic cascade in primary rat adipocytes. Metformin at 250-500 $\mu \mathrm{M}$ efficiently attenuated FFA and glycerol release from the adipocytes stimulated with $1 \mu \mathrm{M}$ isoproterenol. To elucidate the basis for this antilipolytic action, we showed that metformin decreased cellular cAMP production, reduced the activities of PKA and MAPK1/3, and attenuated the phosphorylation of perilipin during isoproterenol-stimulated lipolysis. Further, metformin suppressed isoproterenolpromoted lipase activity but did not affect the translocation of lipase, hormone-sensitive from the cytosol to lipid droplets in adipocytes. This study provides evidence that metformin acts on adipocytes to suppress the lipolysis response to catecholamine. This antilipolytic effect could be a cellular basis for metformin decreasing plasma FFA levels and improving insulin sensitivity.
\end{abstract}

Journal of Molecular Endocrinology (2009) 42, 57-66

\section{Introduction}

Obesity and type 2 diabetes (diabetes mellitus) are associated with elevated levels of plasma free fatty acids (FFA), which restrict glucose utilization and induce insulin resistance (Groop et al. 1989, Bergman \& Ader 2000). The concentration of serum FFA primarily depends on the lipolysis of adipose triacylglycerols that releases FFA and glycerol from adipocytes. Catecholamines are the most important hormones that govern lipolysis through elevating cellular cAMP production and activating cAMP-dependent protein kinase, cAMP dependent, catalytic, alpha (PKA; Londos et al. 1999). PKA then phosphorylates two proteins, hormone-sensitive lipase (HSL) and perilipin, in adipocytes and causes translocation of HSL from the cytosol to the lipid droplet surface, a crucial step for the lipase access to its triacylglycerol substrates (Sztalryd et al. 2003). Perilipin is a structural protein that has a dual role in the control of lipolysis: native perilipins on the lipid droplet surface function as a barrier to prevent
HSL access to the droplet, thus suppressing lipolysis (Sztalryd et al. 2003, He et al. 2006), whereas phosphorylated perilipins allow the translocation of HSL to the lipid droplet for conferring a full lipolytic reaction (Sztalryd et al. 2003). Besides PKA, mitogenactivated protein kinase 1/3 (MAPK1/3; previous aliases: ERK1/2 MAPK) is another important signaling molecule that modulates catecholamine-stimulated lipolysis (Greenberg et al. 2001, Robidoux et al. 2006).

Biguanide metformin is a popular antihyperglycemic drug used to treat diabetes mellitus (Bailey 1992). Unlike sulfonylureas, which stimulate insulin secretion, metformin lowers blood sugar levels by improving insulin sensitivity in peripheral tissues. Metformin increases glucose uptake and disposal in muscle, decreases hepatic glucose production, and also helps combat dyslipidemia (Bailey 1992). Clinical studies suggest that promotion of insulin sensitivity by metformin is associated with an overall reduction in plasma FFA levels in obese and diabetic patients (Riccio et al. 1991, Perriello et al. 1994, Abbasi et al. 1998, 
Hundal et al. 2000). The reduced FFA level is associated with increased glucose disposal. Therefore, the FFA-lowering effect could be essential to mediate the enhanced insulin action of metformin.

The FFA efflux to the bloodstream is governed by the process of adipose lipolysis. To date, information on the direct effect of metformin on adipose lipolysis is scarce and even inconsistent because it was derived from different methodologies. An in vivo study suggested that oral administration of metformin does not affect lipolysis in s.c. adipose tissue of diabetic subjects (Jansson et al. 1996), whereas another in vivo microdialysis study confirmed that direct perfusion of highconcentration $(1 \mathrm{mM})$ metformin into abdominal adipose tissue restricted basal and adrenergic-stimulated glycerol release in obese and diabetic patients (Flechtner-Mors et al. 1999). In vitro studies indicated that metformin at low concentrations $(<25 \mu \mathrm{M})$ did not seem to affect the lipolysis response in isolated adipose tissue (Cigolini et al. 1984), whereas high-dose metfor$\min (>250 \mu \mathrm{M})$ reduced adrenergic-induced lipolysis in primary rat adipocytes (Ren et al. 2006) or in C3H10T1/2 preadipocytes (Lenhard et al. 1997). Our previous study suggested that metformin inhibits the lipolysis response to tumor necrosis factor (TNF) or isoproterenol (Ren et al. 2006). However, the characteristics and basis of the inhibitory effect of metformin on catecholamine-induced lipolysis has not been clarified.

The aim of this study was to investigate the mechanism by which metformin inhibits catecholamine-stimulated lipolysis in adipocytes. We measured the release of FFA and glycerol as an index of lipolysis and examined the major lipolytic signalings in primary adipocytes. Metformin decreased cellular cAMP production, reduced the activities of PKA and MAPK1, and attenuated the phosphorylation of perilipin during isoproterenol-stimulated lipolysis. Further, metformin suppressed isoproterenol-promoted lipase activity without altering the translocation reaction of HSL. This study provides direct evidence that metformin acts on adipocytes to suppress the lipolysis response to catecholamine. This antilipolytic effect could be a cellular basis for metformin decreasing plasma FFA levels and improving insulin sensitivity.

\section{Materials and methods}

\section{Materials}

Isoproterenol and phenol red-free DMEM (fDMEM) containing glucose $(5 \mathrm{mmol} / \mathrm{l})$ were from Sigma Chemical. Metformin was from Bristol-Myers Squibb Pharmaceuticals (Shanghai, China). Enzyme materials used for enzymatic assays were from Toyobo Co. (Tokyo, Japan). Antibodies against MAPK3 and phospho MAPK1/3 and HRP (HRP)-conjugated $\operatorname{lgG}$ were from Santa Cruz Biotechnology (Santa Cruz, CA, USA). Antibodies against rat perilipin and HSL were generous gifts from Dr Londos at the US National Institutes of Health (Bethesda, MD, USA). Nitrocellulose membrane, a prestained protein molecular weight marker, and ultrasensitive enhanced chemiluminescence (ECL) detection reagents were from Applygen Technologies (Beijing, China). The use of animals was approved by the Animal Care and Use Committee of Peking University Health Science Center.

\section{Isolation and culture of primary rat adipocytes}

Adipocytes were isolated from epididymal fat pads of Sprague-Dawley rats (150-180 g) according to our laboratory method (He et al. 2006, Jiang et al. 2007). The minced fat pads were digested in Krebs-Ringer solution containing $0.75 \mathrm{mg} / \mathrm{ml}$ type 1 collagenase, $200 \mathrm{nM}$ adenosine, $25 \mathrm{mM}$ Hepes (pH 7.4), and $1 \%$ defatted BSA. After incubation for $40 \mathrm{~min}$ at $37^{\circ} \mathrm{C}$ in a water bath with shaking at 100 cycles $/ \mathrm{min}$, cells were filtered through a nylon mesh and washed three times with warmed DMEM containing $200 \mathrm{nM}$ adenosine. Adipocytes floating on the top of the tube were packed by centrifuging at $200 \mathrm{~g}$ for $3 \mathrm{~min}$. The packed cell volume (PCV) of the final suspension was determined (He et al. 2006, Jiang et al. 2007). Every $25 \mu \mathrm{l}$ packed adipocytes were resuspended in $500 \mu \mathrm{l}$ serum-free fDMEM containing $2 \%$ defatted BSA and preincubated at $37^{\circ} \mathrm{C}$ for $1 \mathrm{~h}$ prior to treatments (He et al. 2006). Adipocytes were incubated in the presence or absence of the tested agents, and then assayed as described below.

\section{Fatty acid assay}

The concentration of FFA in the culture medium was determined by colorimetric assay as described ( $\mathrm{Zu}$ et al. 2008). Briefly, $50 \mu \mathrm{l}$ culture medium were mixed with $120 \mu \mathrm{l}$ isooctane and $80 \mu \mathrm{l}$ cupric acetate-pyridine, then vortexed and centrifuged for $10 \mathrm{~min}$ at $12000 \mathrm{~g}$ at room temperature. The upper organic phase $(80 \mu \mathrm{l})$ was transferred to a clean tube. An amount of $180 \mu \mathrm{l}$ of the color development reagent consisting of diphenylcarbazone and diphenylcarbazide in methanol was then added to the tube. The mixture was vortexed, and the reaction was developed immediately for color. The absorbance at $540 \mathrm{~nm}$ was spectrophotometrically measured in a 96-well plate.

\section{Glycerol assay}

Glycerol content in the culture medium of adipocytes served as an index of lipolysis and was determined at the 
absorption of $490 \mathrm{~nm}$ (He et al. 2006, Zu et al. 2008) by use of a colorimetric assay ( Trinder reaction) kit from Applygen Technologies. Lipolysis data were expressed as micromoles of glycerol or FFA per milliliter of PCV of adipocytes.

\section{Western blot analysis}

Adipocytes were packed and lysed in sample buffer containing $62 \mathrm{mM}$ Tris- $\mathrm{HCl}(\mathrm{pH} 6 \cdot 8), 5 \%$ SDS, $0 \cdot 1 \mathrm{mM}$ sodium orthovanadate, and $50 \mathrm{mM}$ sodium fluoride. After centrifugation at $12000 \mathrm{~g}$ for $10 \mathrm{~min}$ at $4{ }^{\circ} \mathrm{C}$, the lysate was collected, and the protein content was determined by use of a bicinchoninic acid protein assay kit (Applygen Technologies). Then, the lysate was included in the sample buffer $(62 \mathrm{mM}$ Tris-HCl (pH 6.8), $5 \%$ SDS, $1.7 \% \quad \beta$-mercaptoethanol, $0 \cdot 04 \%$ bromophenol blue, and $10 \%$ glycerol, in final; He et al. 2006, Jiang et al. 2007). After a denaturing at $95^{\circ} \mathrm{C}$ for 5 min, equal amounts of proteins were loaded and separated by $10 \%$ SDS-PAGE. For immunoblotting of phosphorylated perilipin, a low-bis concentration polyacrylamide gel $(10 \%$ acrylamide and $0.07 \%$ $\mathrm{N}, \mathrm{N}^{\prime}$-methylene-bis-acrylamide) was used, which provides better resolution of proteins in the $60-70 \mathrm{kDa}$ range (He et al. 2006). After electrophoresis, the proteins were transferred to nitrocellulose membranes. The membranes were blocked for $1 \mathrm{~h}$ in $5 \%$ non-fat milk in TBS-T buffer $(150 \mathrm{mM} \mathrm{NaCl}, 20 \mathrm{mM}$ Tris-HCl (pH 7.4), and $0.05 \%$ Tween-20), incubated with primary antibodies for $1 \mathrm{~h}$ at room temperature or overnight at $4{ }^{\circ} \mathrm{C}$, then incubated for $1 \mathrm{~h}$ with HRPconjugated secondary antibodies (Xu et al. 2005, 2006). The blots were developed by use of an ECL detection kit. If required, antibodies bound to membranes were removed by a commercial Stripping Solution from Applygen Technologies, and the blots were then reprobed. Densitometric analysis of protein bands involved use of NIHimage software.

\section{CAMP RIA}

As we previously described ( $\mathrm{Zu}$ et al. 2008), adipocytes were lysed in $150 \mu \mathrm{l}$ ice-cold buffer containing $50 \mathrm{mM}$ Tris-HCl (pH 7.4), and $1 \mathrm{mM}$ EDTA. After vortexing and centrifugation at $12000 \mathrm{~g}$ for $15 \mathrm{~min}$ at $4{ }^{\circ} \mathrm{C}$, the cytosolic fraction was collected and the protein content was determined. Then, $90 \mu \mathrm{l}$ cytosol fraction were mixed with $30 \mu \mathrm{l} 40 \%$ trichloroacetic acid. The tubes were vortexed and centrifuged at $12000 \mathrm{~g}$ for $5 \mathrm{~min}$ at $4{ }^{\circ} \mathrm{C}$. The supernatant was collected and used for cAMP assay according to the protocol of a commercial ${ }^{125}$ I RIA kit (Isotope Laboratory of Shanghai University of Chinese Medicine, Shanghai, China). cAMP concentration was normalized and expressed as picomoles per milligram of cytosolic proteins.

\section{Assay of PKA activity ratios}

An amount of $50 \mu \mathrm{l}$ packed adipocytes was added in $150 \mu \mathrm{l}$ ice-cold homogenization buffer containing $50 \mathrm{mM}$ Tris- $\mathrm{HCl}$ (pH 7.4), $1 \mathrm{mM}$ EDTA, and $1 \mathrm{mM}$ 3-isobutyl-1-methylxanthine. The cells were homogenized by ten strokes with a ground glass pestle in a $1 \mathrm{ml}$ ground glass homogenizing tube. The homogenate was transferred immediately to a precooled $1.5 \mathrm{ml}$ tube and centrifuged at $10000 \mathrm{~g}$ for $15 \mathrm{~min}$ at $4{ }^{\circ} \mathrm{C}$ to prepare the cytosolic fraction. Corrected PKA activity ratio, which more faithfully reflects the true activity of cAMP-dependent PKA in response to lipolytic or antilipolytic stimulators in adipocytes (Honnor et al. $1985 a, b)$, was determined and calculated as described (Honnor et al. 1985a) with minor modifications. Briefly, $20 \mu \mathrm{l}$ of the cytosolic extract were added to a tube at $4{ }^{\circ} \mathrm{C}$, and the assay medium was added for a final volume of $50 \mu \mathrm{l}$. PKA activity in each cytosol extract was assayed six times under three separate conditions: a) in a quiescent reaction consisting of $50 \mathrm{mM}$ Tris- $\mathrm{HCl}$ (pH 7.4), $10 \mathrm{mM} \mathrm{MgCl} 2,1 \mathrm{mM}$ 3-isobutyl-1-methylxanthine, $20 \mu \mathrm{Ci} / \mathrm{ml} \gamma-{ }^{32} \mathrm{P}$-ATP, $0 \cdot 3 \mathrm{mM}$ ATP, and $100 \mu \mathrm{M}$ Kemptide (a specific PKA substrate); b) a stimulatory condition consisting of reaction (a) in the presence of $2 \mu \mathrm{M}$ cAMP to activate PKA; and c) an inhibitory condition consisting of reaction (a) in the presence of $10 \mu \mathrm{M}$ PKI inhibitor to suppress PKA. The reactions were incubated for $10 \mathrm{~min}$ at $30^{\circ} \mathrm{C}$, and then terminated by cooling the tubes in a $0-4{ }^{\circ} \mathrm{C}$ ice bath. Then, $40 \mu \mathrm{l}$ of reaction mixture were collected and spread on a P81 phosphocellulose filter (diameter $2.5 \mathrm{~cm}$ ). The filter was washed for $4 \times 5 \mathrm{~min}$ with ice-cold $75 \mathrm{mM}$ phosphoric acid, then underwent $2 \times 5 \mathrm{~min}$ washes with $100 \%$ ethanol. The filter paper was air dried and placed into $3 \mathrm{ml}$ liquid scintillation fluid for counting the ${ }^{32} \mathrm{P}$ radioactivity. Results are expressed as corrected PKA activity ratio $(\mathrm{a}-\mathrm{c}) /(\mathrm{b}-\mathrm{c}$; Honnor et al. $1985 a)$.

\section{Assay of adipose lipase activity}

An amount of $50 \mu \mathrm{l}$ packed adipocytes was lysed in $120 \mu \mathrm{l}$ buffer containing $50 \mathrm{mM}$ Tris- $\mathrm{HCl}(\mathrm{pH} \mathrm{7.4)}$ ), and $1 \mathrm{mM}$ EDTA. The lysate was vortexed and centrifuged at $12000 \mathrm{~g}$ for $15 \mathrm{~min}$ at $4{ }^{\circ} \mathrm{C}$. The infranatant phase below the fat cake fraction was transferred to a new tube and then centrifuged at $12000 \mathrm{~g}$ for $5 \mathrm{~min}$ at $4{ }^{\circ} \mathrm{C}$. The supernatant was used for the determination of cellular lipase activity against emulsified triolein substrate. The mixture was incubated for $30 \mathrm{~min}$ at $37^{\circ} \mathrm{C}$, when the lipases hydrolyze emulsified triolein to produce glycerol. The release of glycerol from triolein hydrolysis represented the activity of adipose lipase and was assayed as described previously ( $\mathrm{Zu}$ et al. 2008). 


\section{Differentiation of rat preadipocytes and immuno- staining of HSL}

Adipose precursor cells (vascular stromal cell) were isolated from epididymal fat pads and differentiated into adipocytes for 3 days in serum-free DMEM:F12 (1:1) medium supplemented with $5 \mu \mathrm{g} / \mathrm{ml}$ insulin, $33 \mu \mathrm{M}$ biotin, and $200 \mathrm{pM}$ triiodothyronine, as we described previously (He et al. 2006, Jiang et al. 2007). The differentiated adipocytes (day 5) were treated with metformin, isoproterenol, or both. Immunostaining was performed according to prior methods. The cells were fixed for $20 \mathrm{~min}$ with $4 \%$ paraformaldehyde and $0.01 \%$ Triton X-100 in PBS buffer at room temperature, then rinsed three times (Xu et al. 2005, He et al. 2006) for $5 \mathrm{~min}$ each with PBS. Nonspecific binding sites in the cells were blocked with $2 \%$ donkey serum for $60 \mathrm{~min}$ and washed three times for $5 \mathrm{~min}$ each. The cells were incubated with rabbit polyclonal serum against HSL at 1:500 overnight at $4{ }^{\circ} \mathrm{C}$ and then with FITC-conjugated donkey anti-rabbit IgG at 1:300 for $2 \mathrm{~h}$ in the darkness at room temperature. Immunofluorescent signaling of HSL was observed with use of a Nikon Eclipse TE2000-U microscope.

\section{Statistical analysis}

Data are expressed as means \pm s.E.M. One-way ANOVA Tukey's test was used for statistical analysis. A $P<0.05$ was considered statistically significant.
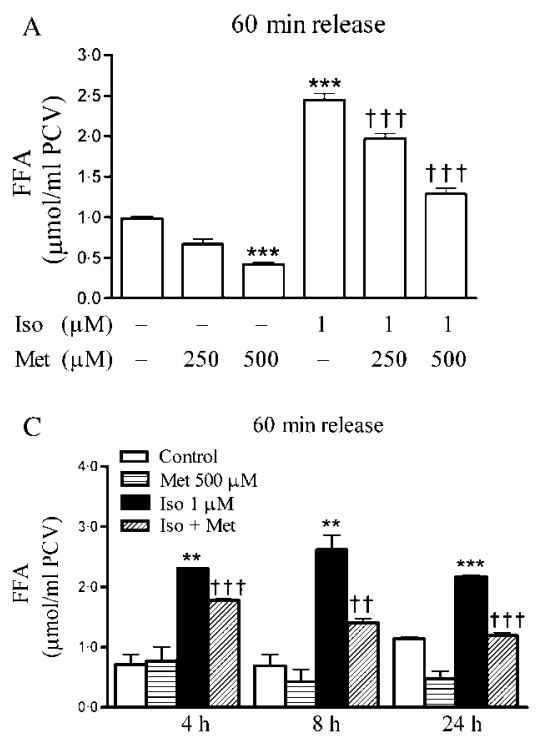

Figure 1 Metformin inhibits the release of FFA and glycerol from primary adipocytes stimulated by isoproterenol. Primary rat adipocytes were preincubated for $6 \mathrm{~h}(\mathrm{~A}$ and $\mathrm{B})$ or for the indicated times (C and D) in the presence or absence of 250 or $500 \mu \mathrm{M}$ metformin (Met), then washed and stimulated with $1 \mu \mathrm{M}$ isoproterenol (Iso) under fresh medium. The 60 min release of FFA ( $A$ and $C$ ) and 30 min release of glycerol ( $B$ and $D$ ) was measured. The data are expressed as micromoles of FFA or glycerol per milliliter packed cell volume (PCV) of adipocytes. Results are means \pm S.E.M. of three separate experiments performed in triplicate. ${ }^{\star}, P<0.05$, ${ }^{\star \star}, P<0.01$ and ${ }^{\star \star *}, P<0.001$ versus control; $\dagger, P<0.05$,

††, $P<0.01$ and †††, $P<0.001$ versus Iso alone.

\section{Metformin inhibited isoproterenol-stimulated lipoly- sis in primary adipocytes}

Hydrolysis of triacylglycerol by cellular lipases results in the release of FFA and glycerol from fat cells. To determine the antilipolytic effect of metformin on isoproterenol-stimulated lipolysis, we measured the levels of FFA and glycerol, an index of lipolysis, released in the incubation medium. Primary rat adipocytes were incubated for the indicated periods in the presence or absence of 250 or $500 \mu \mathrm{M}$ metformin, then the media were replaced with warm fDMEM before $1 \mu \mathrm{M}$ isoproterenol was added for stimulation for $30 \mathrm{~min}$ for glycerol assay (Fig. 1B and D) or $60 \mathrm{~min}$ for FFA measurement (Fig. 1A and C). Preincubation with metformin at 500 but not $250 \mu \mathrm{M}$ readily inhibited the basal FFA efflux (Fig. 1A and C) but not the basal glycerol release from unstimulated adipocytes (Fig. 1B). However, metformin at both 250 and $500 \mu \mathrm{M}$ suppressed isoproterenol-stimulated release of FFA (Fig. 1A) and glycerol (Fig. 1B) from adipocytes. Metformin at $100 \mu \mathrm{M}$ or less had no significant effect on the basal or isoproterenol-stimulated lipolysis (data not shown). Next, preincubation with $500 \mu \mathrm{M}$ metfor$\min$ for $4 \mathrm{~h}$ readily attenuated isoproterenol-mediated release of FFA (Fig. 1C) and glycerol (Fig. 1D). At 8 or
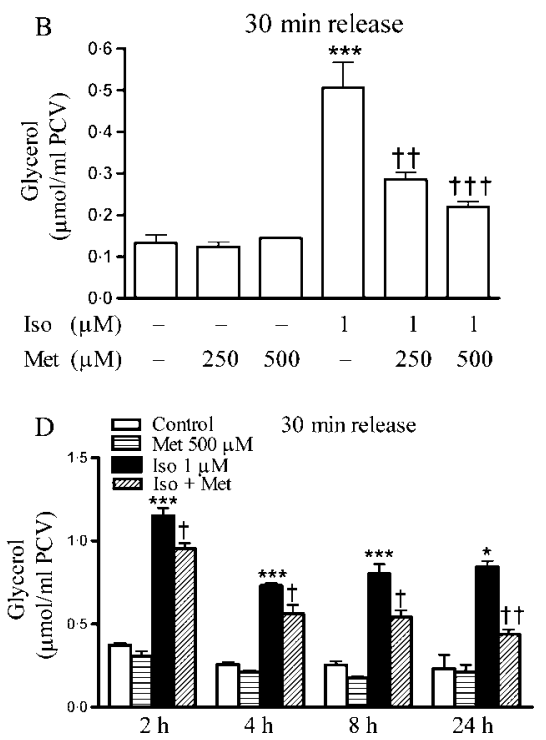
$24 \mathrm{~h}$ of pretreatment, metformin blunted basal or isoproterenol-induced lipolysis (Fig. 1C and D).

\section{Metformin suppressed elevated cAMP level mediated by isoproterenol}

Isoproterenol is well known to stimulate lipolysis primarily through postreceptoral activation of adenylyl cyclase and elevation of intracellular cAMP level in adipocytes (Londos et al. 1999). To elucidate the mechanism whereby metformin inhibits isoproterenol-stimulated lipolysis, we performed a cAMP immunoradioassay to measure the cAMP levels in primary rat adipocytes. Adipocytes were preincubated for $16 \mathrm{~h}$ with or without $500 \mu \mathrm{M}$ metformin, then washed and stimulated for $15 \mathrm{~min}$ with $100 \mathrm{nM}$ isoproterenol in the freshly changed medium. Pretreatment with metformin alone slightly decreased the cAMP content by $27 \%$ in adipocytes (Fig. 2A); a short stimulation (15 min) with $100 \mathrm{nM}$ isoproterenol significantly elevated intracellular cAMP level by $\sim 48 \%(P<0 \cdot 05)$. However, isoproterenol failed to promote cAMP content in adipocytes that were pretreated with metformin $(P<0 \cdot 001)$. The inhibitory effect of metformin on cAMP level was consistent with and parallel to its antilipolytic action in adipocytes by reducing the level of glycerol (Fig. 2B).

\section{Metformin restricted the elevation of PKA activity on isoproterenol stimulation}

Elevated intracellular cAMP level causes activation of PKA, which activates subsequent signalings in the lipolytic cascade, therefore conferring a full lipolytic response (Londos et al. 1999). The corrected PKA activity ratio more faithfully reflects the true activity of cAMP-dependent PKA upon lipolytic or antilipolytic stimulations (Honnor et al. 1985a,b). We examined the alteration in corrected PKA activity ratio in the cytosol fraction from adipocytes in response to isoproterenol, metformin, or both (Honnor et al. 1985a). Adipocytes were pretreated for $16 \mathrm{~h}$ with or without $500 \mu \mathrm{M}$ metformin, then washed and stimulated for $15 \mathrm{~min}$ by $1 \mu \mathrm{M}$ isoproterenol. Isoproterenol increased the PKA activity ratio by threefold $(P<0.01)$ in adipocytes. By contrast, pretreatment with metformin did not alter the basal PKA activity ratio but completely suppressed the isoproterenol-promoted PKA activity ratio in adipocytes $(P<0 \cdot 001$, Fig. 3A). In parallel to the inhibitory effect of metformin on activating PKA with isoproterenol stimulation, the level of glycerol released in the incubation medium was reduced, which indicated that metformin attenuated isoproterenol-stimulated lipolysis (Fig. 3B).
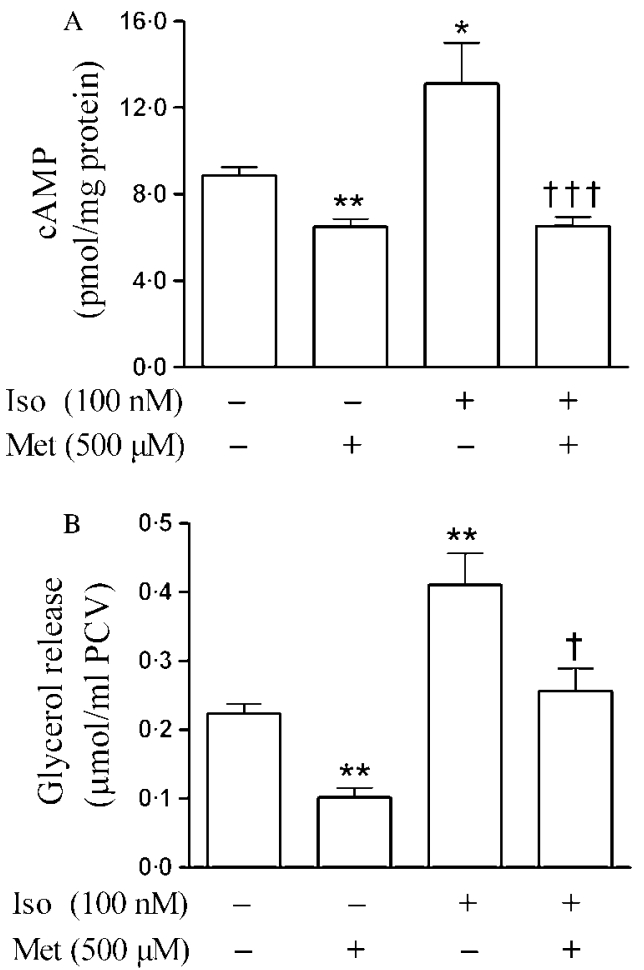

Figure 2 Effects of isoproterenol and metformin on intracellular cAMP levels and lipolysis. Primary rat adipocytes were preincubated for $16 \mathrm{~h}$ in the presence or absence of $500 \mu \mathrm{M}$ metformin (Met), then washed, and stimulated with $100 \mathrm{nM}$ isoproterenol (Iso) under fresh medium for $15 \mathrm{~min}$ prior to the ${ }^{125}$ I-RIA assay of cellular CAMP content (A) or for $30 \mathrm{~min}$ prior to the measurement of glycerol (B). Results (means \pm s.E.M.) are representative of three separate experiments performed six times (A) or three times (B). ${ }^{*}, P<0.05$ and ${ }^{* *}, P<0.01$ versus control; †, $P<0.05$ and $\dagger \dagger \dagger, P<0.001$ versus Iso alone.

Besides the cAMP/PKA cascade, the activation of MAPK1/3 signaling is another important event during catecholamine-stimulated lipolysis (Greenberg et al. 2001, Robidoux et al. 2006). We performed immunoblotting analysis to examine whether metformin affected the phosphorylation of MAPK1/3 in primary adipocytes. Adipocytes were preincubated for $2 \mathrm{~h}$ with $500 \mu \mathrm{M}$ metformin and then stimulated for $5 \mathrm{~min}$ with $100 \mathrm{nM}$ isoproterenol. Exposure of adipocytes to isoproterenol promoted MAPK1/3 phosphorylation by $\sim 41 \% \quad(P<0 \cdot 01)$; metformin remarkably attenuated isoproterenol-mediated MAPK1/3 phosphorylation $(P<0 \cdot 01$; Fig. $4 \mathrm{~A}$ and $\mathrm{B})$. Neither isoproterenol nor metformin altered the level of total MAPK3 proteins (Fig. 4A).

\section{Metformin decreased perilipin phosphorylation on isoproterenol stimulation}

Perilipin proteins coat the surface of the lipid droplets to function as a barrier to protect the triglycerides in 


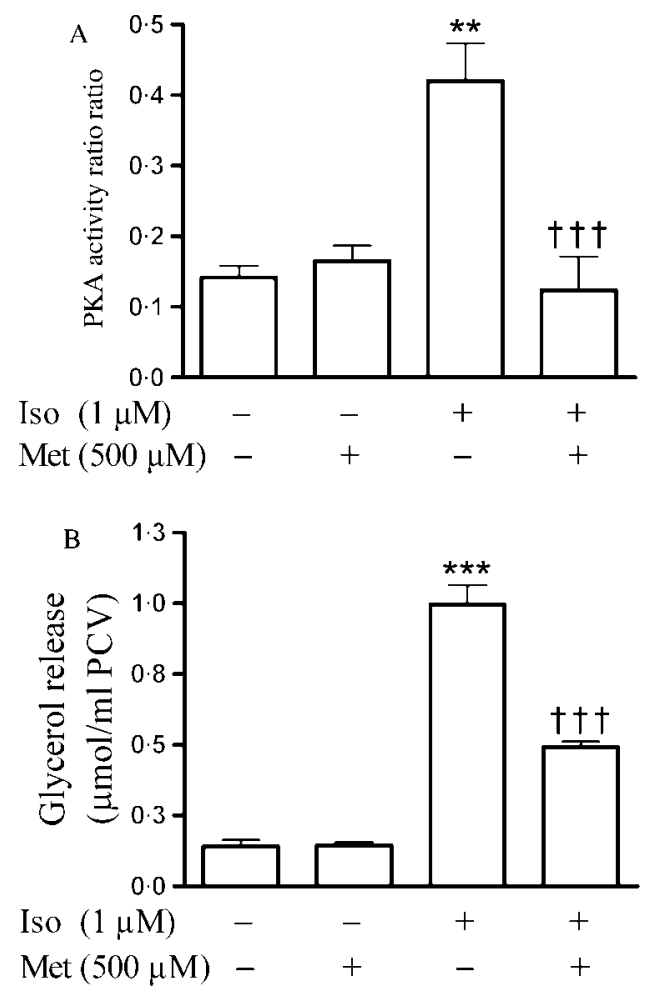

Figure 3 Metformin restricts the elevation of PKA activity on isoproterenol stimulation. Isolated primary adipocytes were preincubated for $16 \mathrm{~h}$ with or without $500 \mu \mathrm{M}$ metformin (Met), and then washed, and medium was changed to fresh medium.

(A) Adipocytes were stimulated with $1 \mu \mathrm{M}$ isoproterenol (Iso) for $15 \mathrm{~min}$, and then homogenized to prepare the cytosolic fraction. PKA activity in each cytosol extract was assayed six times under three separate conditions, and the corrected PKA activity ratio was calculated as described in Methods. Values are expressed as means \pm S.E.M. of three separate experiments performed six times. (B) Glycerol released in the incubation medium was assayed in parallel. ${ }^{* *}, P<0.01$ and ${ }^{* *}, P<0.001$ versus control; †††, $P<0.001$ versus Iso.

the droplet from hydrolysis by cellular lipases (Londos et al. 2005). When perilipin is phosphorylated by PKA, its barrier function ceases and the lipolysis reaction is initiated (Sztalryd et al. 2003, Londos et al. 2005, He et al. 2006). We examined the phosphorylation status of perilipin in adipocytes in response to isoproterenol, metformin, or both. Adipocytes were preincubated for $12 \mathrm{~h}$ in the presence or absence of $500 \mu \mathrm{M}$ metformin and then stimulated for $5 \mathrm{~min}$ with $1 \mu \mathrm{M}$ isoproterenol. Adipocytes were lysed and protein extracts underwent immunoblotting with primary antibodies against perilipin. The addition of isoproterenol to adipocytes caused a migration shift of perilipin bands from 65 to $\sim 67 \mathrm{kDa}$ on a low-bis concentration of SDS-polyacrylamide gel (Fig. 5); this electrophoretic shift pattern was previously shown to result from the phosphorylation of perilipin proteins mediated by PKA (Egan et al. 1990) or non-PKA stimulation of adipocytes (Sengenes et al. 2003,

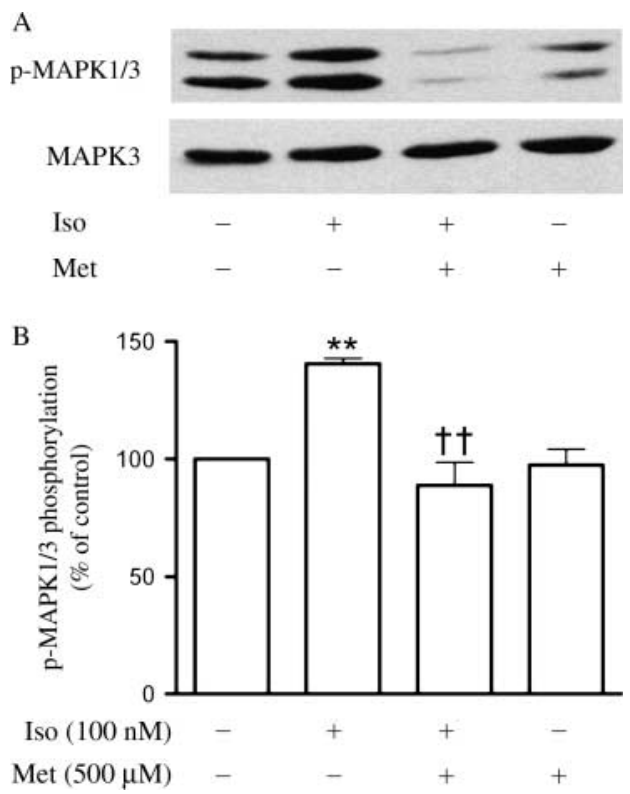

Figure 4 Inhibition of MAPK $1 / 3$ activation by metformin during isoproterenol-stimulated lipolysis. Adipocytes were preincubated for $2 \mathrm{~h}$ with $500 \mu \mathrm{M}$ metformin (Met), then stimulated with $100 \mathrm{nM}$ isoproterenol (Iso) for $5 \mathrm{~min}$. Adipocytes were lysed and proteins underwent immunoblotting with use of primary antibodies against phosphorylated-MAPK1/3 (p-MAPK1/3) and HRP-conjugated secondary antibodies. To detect total MAPK1, blots were stripped and reprobed with primary anti-MAPK3 antibodies (MAPK3). The phosphorylated-MAPK $1 / 3$ levels were densitometrically quantitated against total MAPK3 levels. The data are from three separate experiments and expressed as percentage of the control. ${ }^{*}, P<0.01$ versus control; $\dagger \dagger, P<0.01$ versus Iso alone.

Aboulaich et al. 2006, He et al. 2006). Preincubation with metformin did not alter the status of basal perilipin phosphorylation in unstimulated cells but inhibited the isoproterenol-mediated perilipin phosphorylation, as evidenced by the appearance of a weak $65 / 67 \mathrm{kDa}$ doublet (Fig. 5). Complete abolishment of PKA activity (Fig. 3A) but incomplete abrogation of perilipin phosphorylation (Fig. 5) by metformin implicates that

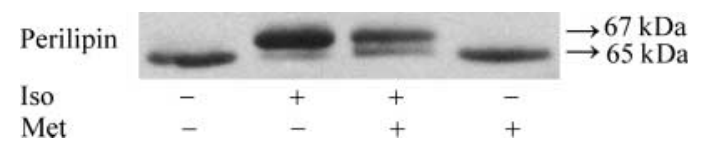

Figure 5 Metformin inhibited perilipin phosphorylation on isoproterenol stimulation. Isolated adipocytes were preincubated for $12 \mathrm{~h}$ in the presence or absence of $500 \mu \mathrm{M}$ metformin (Met), then washed and stimulated for 5 min with $1 \mu \mathrm{M}$ isoproterenol (Iso) under fresh medium. Adipocytes were lysed and proteins were separated on a low-bis concentration of SDS-polyacrylamide gel, which provides better resolution of proteins in the $60-70 \mathrm{kDa}$ range. The proteins transferred on nitrocellulose membranes were immunoblotted with primary antibodies against rat perilipin and HRP-conjugated secondary antibodies. The electrophoretic shift of native perilipin at $65 \mathrm{kDa}$ to its hyperphosphorylated form at $\sim 67 \mathrm{kDa}$ was a result of isoproterenol stimulation. The blot shown is representative of three separate experiments. 
perilipin could be also phosphorylated, as yet not clarified, in a PKA-independent manner in isoproterenol-stimulated adipocytes.

\section{Effect of metformin on lipase activity, translocation, and protein expression}

The last step of lipolysis activation by PKA stimulation with isoproterenol is the process of hydrolysis of triglycerides by two major cellular lipases, HSL and adipose triglyceride lipase (ATGL; Londos et al. 1999, Schweiger et al. 2006). Therefore, we investigated the influence of metformin on total activity of adipocyte lipases. Isolated adipocytes were preincubated for $12 \mathrm{~h}$ with or without $500 \mu \mathrm{M}$ metformin, and then stimulated for $20 \mathrm{~min}$ with $100 \mathrm{nM}$ isoproterenol.
Isoproterenol promoted total lipase activity by $\sim 96 \%$ compared with that in controls $(P<0 \cdot 01$, Fig. 6A). Metformin preincubation did not affect basal lipase activity in unstimulated adipocytes but greatly reduced isoproterenol-activated lipase activity (Fig. 6A).

During lipolysis activated by PKA, the translocation of HSL from the cytosol to the lipid droplet surface is a key factor in lipolysis modulation (Londos et al. 1999, Sztalryd et al. 2003). We next differentiated rat preadipocytes to mature adipocytes and performed immunofluorescent staining of HSL. Immunofluorescent signals for HSL were dispersed throughout the cytoplasm in unstimulated differentiating adipocytes but translocated to the surface (ring loop) of the intracellular lipid droplets after 5 min stimulation with $1 \mu \mathrm{M}$ isoproterenol (Fig. 6B). Short or prolonged pretreatment with $500 \mu \mathrm{M}$ metformin

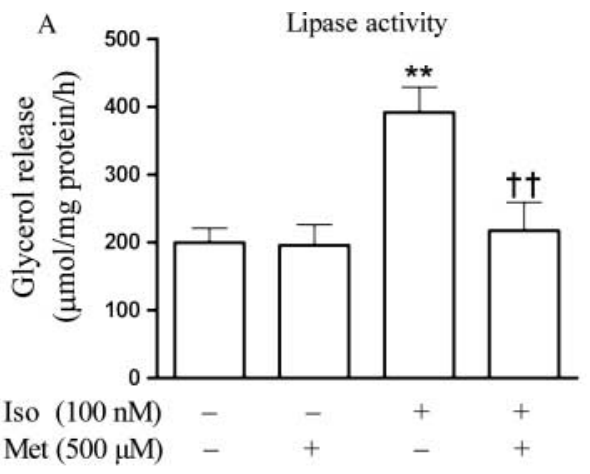

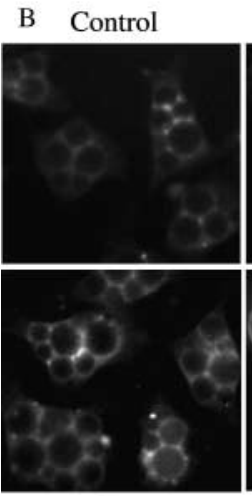

Met
Iso

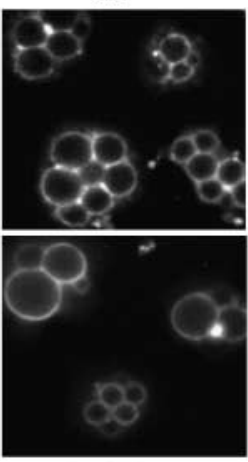

Iso+Met

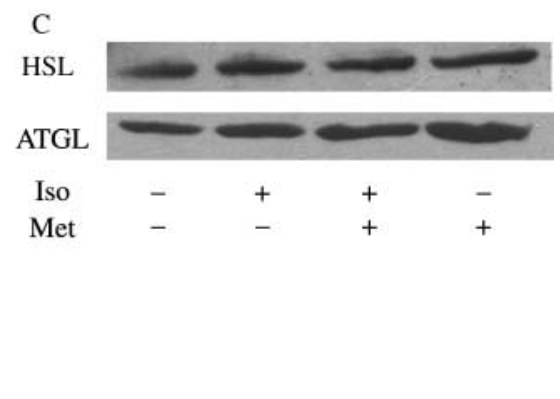

Figure 6 Effect of metformin on lipase activity, translocation, and protein expression. (A) Lipase activity. Primary rat adipocytes were preincubated for $12 \mathrm{~h}$ with or without $500 \mu \mathrm{M}$ metformin (Met), then stimulated with $100 \mathrm{nM}$ isoproterenol (Iso) for $20 \mathrm{~min}$. The cellular lipase activity in the cytosolic fraction of adipocytes was determined. Results are means \pm S.E.M. of three individual experiments performed in triplicate. ${ }^{*}, P<0.01$ versus control; ††, $P<0.01$ versus Iso. (B) Immunofluorescence of HSL. Rat preadipocytes were isolated and differentiated into adipocytes. On day 5 , differentiated adipocytes were incubated with or without $500 \mu \mathrm{M}$ metformin (Met) for $24 \mathrm{~h}$, then washed and stimulated for 5 min with $1 \mu \mathrm{M}$ isoproterenol (Iso) under fresh medium. Immunostaining was performed by use of anti-HSL antibody and FITC-conjugated second antibody. (C) Immunoblot. Primary rat adipocytes were incubated with $500 \mu \mathrm{M}$ metformin for $24 \mathrm{~h}$, then stimulated with $1 \mu \mathrm{M}$ isoproterenol for $30 \mathrm{~min}$. Protein extracts of the lysed adipocyte underwent immunoblotting with primary antibodies against rat HSL or ATGL and HRP-conjugated secondary antibodies. The blots shown are representative of three separate experiments. 
for 12 (data not shown) or for $24 \mathrm{~h}$ (Fig. 6B) seemed to slightly increase the assembly of HSL to the lipid droplet periphery, but did not inhibit the HSL translocation induced by isoproterenol (Fig. 6B). Finally, immunoblotting results indicated that metformin did not alter the protein levels of the two major cellular lipases, ATGL and HSL, in primary adipocytes (Fig. 6C).

\section{Discussion}

The major goals of the present study were to elucidate the pharmacological characteristics and cellular basis of the inhibitory effect of metformin on adrenergicstimulated lipolysis in primary rat adipocytes.

The therapeutic concentrations of metformin are between 10 and $2000 \mu \mathrm{M}$ in human or diabetic animals (Pentikainen 1986, Bailey \& Turner 1996, Wang et al. 2003). In the present study, metformin exhibited concentration- and time-dependent antilipolytic effects in primary rat adipocytes. Incubation with metformin at $500 \mu \mathrm{M}$ but not $250 \mu \mathrm{M}$ effectively reduced basal lipolysis and inhibited FFA efflux from unstimulated adipocytes, whereas at $250-500 \mu \mathrm{M}$, it largely attenuated FFA and glycerol release from isoproterenolstimulated adipocytes. These antilipolytic effects occurred early, at $4 \mathrm{~h}$ after the addition of metformin. Previous studies indicated that low concentrations of metformin (2-4 mg/l, equivalent to $12-24 \mu \mathrm{mol} / \mathrm{l})$ failed to inhibit norepinephrine-stimulated lipolysis in isolated human adipose tissue (Cigolini et al. 1984); by contrast, perfusion of metformin at high concentrations $(1 \mathrm{mM})$ directly into abdominal adipose tissues of obese and diabetic subjects inhibited basal and adrenergic-stimulated glycerol release (Flechtner-Mors et al. 1999). Moreover, our previous study demonstrated that metformin at $500 \mu \mathrm{M}$ effectively inhibited the lipolysis response to TNF or excess glucose in primary rat adipocytes (Ren et al. 2006). These data confirm that adipose tissue is another target in addition to muscle and liver for metformin to act on. Therefore, the administration of relatively high-dose metformin in diabetic patients may sufficiently restrict the basal and stimulated lipolysis response to catecholamine or TNF. This antilipolytic action, which decreases FFA efflux from adipose cells, could be the cellular basis by which metformin reduces serum FFA levels and hence increases insulin sensitivity. In addition, the lipolytic effect of catecholamines is more pronounced in visceral than s.c. fat tissues (Arner et al. 1990), which leads to more FFA efflux to the portal venous system and directly provides a substrate for hepatic lipoprotein metabolism or glucose production. The reduction of the catecholamine-induced lipolytic rate by metformin may prevent the ectopic lipid accumulation and, hence, further improve insulin resistance.
Catecholamines are the most important lipolytic hormones. The early events for catecholamine-stimulated lipolysis in adipocytes are cAMP elevation and PKA activation (Londos et al. 1999), as confirmed by the present study. In unstimulated adipocytes, metformin alone inhibited basal lipolysis but only slightly decreased basal cAMP level and did not alter PKA activity. However, metformin significantly inhibited cellular cAMP elevation, suppressed PKA activation, and thus attenuated the lipolysis response to isoproterenol stimulation in adipocytes. Besides activation of PKA, that of MAPK1/3 is required for maximal lipolytic activity on adrenergic stimulation (Greenberg et al. 2001, Robidoux et al. 2006). Metformin attenuated the basal and isoproterenolmediated MAPK1/3 phosphorylation without affecting the total MAPK3 protein level; these effects are similar to our previous observations of metformin inhibiting MAPK1/3 phosphorylation and lipolysis mediated by TNF in adipocytes (Ren et al. 2006). In addition to MAPK1/3, there are two other mitogen-activated protein kinases (MAPKs), mitogen-activated protein kinase 8 (MAPK8), and p38 MAPK. We observed that the phosphorylated MAPK8 was rarely detectable in primary rat adipocytes, and the phosphorylation of p38 MAPK was not apparently affected by isoproterenol (unpublished data) but was modestly promoted by metformin (Ren et al. 2006). Therefore, inhibition of MAPK1/3 activation on isoproterenol stimulation may be another basis for the antilipolytic action of metformin.

Perilipin is the most abundant protein coating the surface of the lipid droplets in adipocytes, which may function as a barrier to limit triacylglycerol hydrolysis by lipases (Londos et al. 1999). Also, phosphorylation of perilipin is associated with the localization of HSL on the lipid droplet (Granneman et al. 2007). Upon catecholamine stimulation, PKA-phosphorylated perilipin is required for HSL translocation from the cytosol to the lipid droplets, thus facilitating lipolysis (Sztalryd et al. 2003). Moreover, PKA-independent hyperphosphorylation of perilipins is sufficient to confer a full lipolytic reaction without inducing HSL translocation in adipocytes, whereas lipolysis ceases with inhibited perilipin hyperphosphorylation (He et al. 2006). In our study, metformin inhibited perilipin phosphorylation on lipolytic stimulation with isoproterenol. This effect could mainly result from metformin inhibiting isoproterenol-promoted PKA activity. Surprisingly, when metformin inhibited PKA activation and perilipin phosphorylation and efficiently attenuated increase of the lipase activity, it failed to eliminate isoproterenolinduced HSL translocation to the lipid droplets in adipocytes. Perhaps, this finding was due to metformin being unable to completely abrogate the PKA phosphorylation of perilipin; hence HSL translocation remained. Conversely, MAPK1/3 activation, which promotes HSL activity but does not induce HSL 
translocation, was found to be responsible for adrenergic-stimulated lipolysis, of $\sim 30 \%$, in a PKA -independent manner (Greenberg et al. 2001, Robidoux et al. 2006). As well, inhibition of MAPK1/3 was found to diminish lipolysis by $50 \%$ but did not prevent HSL translocation to the lipid droplet (Robidoux et al. 2006). Therefore, if MAPK1/3 inhibition accounts for a greater proportion of the mediation of the antilipolytic action of metformin, metformin could inhibit lipolysis without altering the HSL translocation. Metformin inhibited MAPK1/3 activation and also largely suppressed the cellular lipase activity elevated by isoproterenol. By contrast, neither isoproterenol nor metformin affected the protein levels of HSL and ATGL. HSL, together with ATGL, constitutes more than $95 \%$ of triglyceride hydrolase activity in white adipocytes; ATGL is not phosphorylated by PKA but is assumed to contribute most of the non-HSL activity during catecholamine-stimulated lipolysis (Zimmermann et al. 2004, Schweiger et al. 2006). The phosphorylation of perilipin is required for ATGL-catalyzed lipolytic activity (Miyoshi et al. 2007); thus, the inhibition of perilipin phosphorylation by metformin may account for the decrease in the non-HSL lipase activity. The lipase triacylglycerol hydrolase mainly regulates basal but not stimulated lipolysis (Wei et al. 2007); whether the inhibitory effect of metformin on basal lipolysis is related to triacylglycerol hydrolase requires further investigation.

Protein kinase, AMP-activated, alpha 1 catalytic subunit (AMPK) is a major metabolic modulator that can be activated by catecholamines and biguanide. The activation of AMPK regulates metformin-mediated glucose and lipid metabolism (Zhou et al. 2001). The possible role of AMPK in lipolysis regulation remains controversial. One study suggested that AMPK phosphorylation is responsible for maximal lipolysis in differentiated 3T3-L1 adipocytes (Yin et al. 2003). Other investigators contrarily propose that AMPK is an antilipolytic modulator, because promotion of AMPK activity by phenformin or 5-aminoimidazole-4carboxamide ribonucleoside (AICAR) inhibited isoproterenol-induced lipolysis in primary rat adipocytes (Sullivan et al. 1994, Daval et al. 2005); by contrast, when AMPK is decreased either by a dominant-negative form or in AMPK-null mice, lipolysis is increased (Daval et al. 2005). However, we failed to detect the protein band of phosphorylated or total AMPK in primary rat adipocytes in the presence of metformin and/or isoproterenol (data not shown); thus we were unable to access whether AMPK mediates the antilipolytic action of metformin.

In conclusion, the present study provides direct evidence that metformin inhibits lipolysis through multiple mechanisms by attenuating cAMP-PKA and MAPK1/3 signaling, inhibiting perilipin phosphorylation, and decreasing lipase activity in primary adipocytes in response to catecholamine stimulation. Despite the 50-year use of metformin as an effective antidiabetic drug, its antihyperglycemic effect remains a mystery. Our data reveal that adipose tissue is another important target for metformin to act on. Obviously, the antilipolytic action of metformin reduces FFA mobilization from adipose cells, which could be a cellular basis for metformin in lowering circulation FFA levels and ameliorating insulin sensitivity.

\section{Declaration of interest}

The authors declare that there is no conflict of interest that could be perceived as prejudicing the impartiality of the research reported.

\section{Funding}

This work was supported by the National Basic Research Program of China (2009CB941603 and 2006CB503903); the National Natural Science Foundation of China (30890042, 30770803, and 30670779); and by the Beijing Natural Science Foundation (5072030).

\section{Acknowledgements}

We thank Dr Tingting Ren and Dr Meitang Liu for technical assistance.

\section{References}

Abbasi F, Carantoni M, Chen YD \& Reaven GM 1998 Further evidence for a central role of adipose tissue in the antihyperglycemic effect of metformin. Diabetes Care 21 1301-1305.

Aboulaich N, Vener AV \& Stralfors P 2006 Hormonal control of reversible translocation of perilipin $\mathrm{B}$ to the plasma membrane in primary human adipocytes. Journal of Biological Chemistry 281 11446-11449.

Arner P, Hellstrom L, Wahrenberg H \& Bronnegard M 1990 Betaadrenoceptor expression in human fat cells from different regions. Journal of Clinical Investigation 86 1595-1600.

Bailey CJ 1992 Biguanides and NIDDM. Diabetes Care 15 755-772.

Bailey CJ \& Turner RC 1996 Metformin. New England Journal of Medicine $334574-579$.

Bergman RN \& Ader M 2000 Free fatty acids and pathogenesis of type 2 diabetes mellitus. Trends in Endocrinology and Metabolism 11 351-356.

Cigolini M, Bosello O, Zancanaro C, Orlandi PG, Fezzi O \& Smith U 1984 Influence of metformin on metabolic effect of insulin in human adipose tissue in vitro. Diabetes $\mathcal{E}$ Metabolism 10 311-315.

Daval M, Diot-Dupuy F, Bazin R, Hainault I, Viollet B, Vaulont S, Hajduch E, Ferre P \& Foufelle F 2005 Anti-lipolytic action of AMPactivated protein kinase in rodent adipocytes. Journal of Biological Chemistry $28025250-25257$.

Egan JJ, Greenberg AS, Chang MK \& Londos C 1990 Control of endogenous phosphorylation of the major cAMP-dependent protein kinase substrate in adipocytes by insulin and betaadrenergic stimulation. Journal of Biological Chemistry 265 18769-18775.

Flechtner-Mors M, Ditschuneit HH, Jenkinson CP, Alt A \& Adler G 1999 Metformin inhibits catecholamine-stimulated lipolysis in 
obese, hyperinsulinemic, hypertensive subjects in subcutaneous adipose tissue: an in situ microdialysis study. Diabetic Medicine $\mathbf{1 6}$ $1000-1006$.

Granneman JG, Moore HP, Granneman RL, Greenberg AS, Obin MS \& Zhu Z 2007 Analysis of lipolytic protein trafficking and interactions in adipocytes. Journal of Biological Chemistry 282 5726-5735.

Greenberg AS, Shen WJ, Muliro K, Patel S, Souza SC, Roth RA \& Kraemer FB 2001 Stimulation of lipolysis and hormone-sensitive lipase via the extracellular signal-regulated kinase pathway. Journal of Biological Chemistry 276 45456-45461.

Groop LC, Bonadonna RC, DelPrato S, Ratheiser K, Zyck K, Ferrannini E \& DeFronzo RA 1989 Glucose and free fatty acid metabolism in non-insulin-dependent diabetes mellitus. Evidence for multiple sites of insulin resistance. Journal of Clinical Investigation 84 205-213.

He J, Jiang H, Tansey JT, Tang C, Pu S \& Xu G 2006 Calyculin and okadaic acid promote perilipin phosphorylation and increase lipolysis in primary rat adipocytes. Biochimica et Biophysica Acta 1761 247-255.

Honnor RC, Dhillon GS \& Londos C 1985 a cAMP-dependent protein kinase and lipolysis in rat adipocytes. I. Cell preparation, manipulation, and predictability in behavior. Journal of Biological Chemistry 260 15122-15129.

Honnor RC, Dhillon GS \& Londos C $1985 b$ cAMP-dependent protein kinase and lipolysis in rat adipocytes. II. Definition of steady-state relationship with lipolytic and antilipolytic modulators. Journal of Biological Chemistry 260 15130-15138.

Hundal RS, Krssak M, Dufour S, Laurent D, Lebon V, Chandramouli V, Inzucchi SE, Schumann WC, Petersen KF, Landau BR et al. 2000 Mechanism by which metformin reduces glucose production in type 2 diabetes. Diabetes 49 2063-2069.

Jansson PA, Gudbjornsdottir HS, Andersson OK \& Lonnroth PN 1996 The effect of metformin on adipose tissue metabolism and peripheral blood flow in subjects with NIDDM. Diabetes Care $\mathbf{1 9}$ $160-164$.

Jiang H, He J, Pu S, Tang C \& Xu G 2007 Heat shock protein 70 is translocated to lipid droplets in rat adipocytes upon heat stimulation. Biochimica et Biophysica Acta 1771 66-74.

Lenhard JM, Kliewer SA, Paulik MA, Plunket KD, Lehmann JM \& Weiel JE 1997 Effects of troglitazone and metformin on glucose and lipid metabolism: alterations of two distinct molecular pathways. Biochemical Pharmacology 54 801-808.

Londos C, Brasaemle DL, Schultz CJ, Adler-Wailes DC, Levin DM, Kimmel AR \& Rondinone CM 1999 On the control of lipolysis in adipocytes. Annals of the New York Academy of Sciences 892 155-168.

Londos C, Sztalryd C, Tansey JT \& Kimmel AR 2005 Role of PAT proteins in lipid metabolism. Biochimie 87 45-49.

Miyoshi H, Perfield JW II, Souza SC, Shen WJ, Zhang HH, Stancheva ZS, Kraemer FB, Obin MS \& Greenberg AS 2007 Control of adipose triglyceride lipase action by serine 517 of perilipin A globally regulates protein kinase A-stimulated lipolysis in adipocytes. Journal of Biological Chemistry 282 996-1002.

Pentikainen PJ 1986 Bioavailability of metformin. Comparison of solution, rapidly dissolving tablet, and three sustained release products. International Journal of Clinical Pharmacology, Therapy, and Toxicology 24 213-220.

Perriello G, Misericordia P, Volpi E, Santucci A, Santucci C, Ferrannini E, Ventura MM, Santeusanio F, Brunetti P \& Bolli GB 1994 Acute antihyperglycemic mechanisms of metformin in NIDDM. Evidence for suppression of lipid oxidation and hepatic glucose production. Diabetes 43 920-928.
Ren T, He J, Jiang H, Zu L, Pu S, Guo X \& Xu G 2006 Metformin reduces lipolysis in primary rat adipocytes stimulated by tumor necrosis factor-alpha or isoproterenol. Journal of Molecular Endocrinology 37 175-183.

Riccio A, Del Prato S, Vigili de Kreutzenberg S \& Tiengo A 1991 Glucose and lipid metabolism in non-insulin-dependent diabetes. Effect of metformin. Diabetes and Metabolism 17 180-184.

Robidoux J, Kumar N, Daniel KW, Moukdar F, Cyr M, Medvedev AV \& Collins S 2006 Maximal beta3-adrenergic regulation of lipolysis involves Src and epidermal growth factor receptor-dependent ERK1/2 activation. Journal of Biological Chemistry 281 37794-37802.

Schweiger M, Schreiber R, Haemmerle G, Lass A, Fledelius C, Jacobsen P, Tornqvist H, Zechner R \& Zimmermann R 2006 Adipose triglyceride lipase and hormone-sensitive lipase are the major enzymes in adipose tissue triacylglycerol catabolism. Journal of Biological Chemistry 281 40236-40241.

Sengenes C, Bouloumie A, Hauner H, Berlan M, Busse R, Lafontan M \& Galitzky J 2003 Involvement of a cGMP-dependent pathway in the natriuretic peptide-mediated hormone-sensitive lipase phosphorylation in human adipocytes. Journal of Biological Chemistry $\mathbf{2 7 8}$ 48617-48626.

Sullivan JE, Brocklehurst KJ, Marley AE, Carey F, Carling D \& Beri RK 1994 Inhibition of lipolysis and lipogenesis in isolated rat adipocytes with AICAR, a cell-permeable activator of AMP- activated protein kinase. FEBS Letters 353 33-36.

Sztalryd C, Xu G, Dorward H, Tansey JT, Contreras JA, Kimmel AR \& Londos C 2003 Perilipin A is essential for the translocation of hormone-sensitive lipase during lipolytic activation. Journal of Cell Biology 161 1093-1103.

Wang DS, Kusuhara H, Kato Y, Jonker JW, Schinkel AH \& Sugiyama Y 2003 Involvement of organic cation transporter 1 in the lactic acidosis caused by metformin. Molecular Pharmacology 63 844-848.

Wei E, Gao W \& Lehner R 2007 Attenuation of adipocyte triacylglycerol hydrolase activity decreases basal fatty acid efflux. Journal of Biological Chemistry 282 8027-8035.

Xu G, Sztalryd C, Lu X, Tansey JT, Gan JW, Dorward H, Kimmel AR \& Londos C 2005 Post-translational regulation of adipose differentiation-related protein by the ubiquitin/proteasome pathway. Journal of Biological Chemistry 280 42841-42847.

Xu G, Sztalryd C \& Londos C 2006 Degradation of perilipin is mediated through ubiquitination-proteasome pathway. Biochimica et Biophysica Acta 1761 83-90.

Yin W, Mu J \& Birnbaum MJ 2003 Role of AMP-activated protein kinase in cyclic AMP-dependent lipolysis In 3T3-L1 adipocytes. Journal of Biological Chemistry 278 43074-43080.

Zhou G, Myers R, Li Y, Chen Y, Shen X, Fenyk-Melody J, Wu M, Ventre J, Doebber T, Fujii N et al. 2001 Role of AMP-activated protein kinase in mechanism of metformin action. Journal of Clinical Investigation 108 $1167-1174$.

Zimmermann R, Strauss JG, Haemmerle G, Schoiswohl G, BirnerGruenberger R, Riederer M, Lass A, Neuberger G, Eisenhaber F, Hermetter A et al. 2004 Fat mobilization in adipose tissue is promoted by adipose triglyceride lipase. Science 306 1383-1386.

Zu L, Jiang H, He J, Xu C, Pu S, Liu M \& Xu G 2008 Salicylate blocks lipolytic actions of tumor necrosis factor- $\alpha$ in primary rat adipocytes. Molecular Pharmacology 73 215-223.

Received in final form 13 October 2008

Accepted 27 October 2008

Made available online as an Accepted Preprint 27 October 2008 